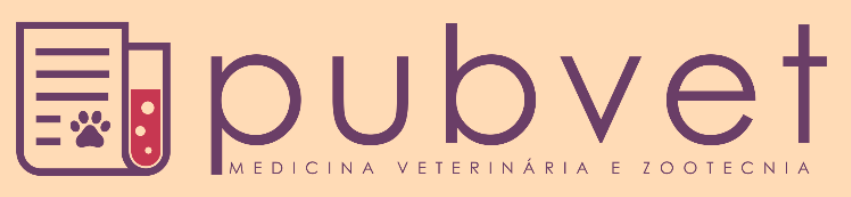

https://doi.org/10.31533/pubvet.v14n9a655.1-7

\title{
Sobrevivência e perfil de resistência a antimicrobianos de isolados de Salmonella sp. em dejeto suíno armazenado
}

\author{
Amanda Dias de Oliveira $^{10}$, Melanie Alice Machado Mansson $^{2}{ }^{\circ}$, Tatiana Regina Vieira ${ }^{30}$, \\ Verônica Schmidt ${ }^{4 *} \bullet$ \\ ${ }^{I}$ Unversidade Federal do Rio Grande do Sul (UFRGS), Programa de pós-graduação em Agronegócios, Porto Alegre-RS, Brasil. \\ ${ }^{2}$ UFRGS, Faculdade de Agronomia, Graduação em Zootecnia. \\ ${ }^{3}$ UFRGS, Faculdade de Veterinária, Programa de Pós-graduação em Ciência Veterinárias. \\ ${ }^{4}$ Professor Titular, UFRGS, Departamento de Medicina Veterinária Preventiva, Porto Alegre-RS, Brasil \\ *Autor para correspondência, E-mail: veronica.schmidt@ufrgs.br
}

Resumo. Este estudo teve como objetivos determinar a sobrevivência e o perfil de resistência a antimicrobianos de amostras de Salmonella sp. isoladas de seis sistemas de armazenamento de dejetos suínos. Determinou-se o perfil de resistência a antimicrobianos de isolados de Salmonella sp. provenientes de esterqueiras com capacidade de armazenamento de dejetos suínos por um período mínimo de 120 dias. Das 63 amostras de dejetos analisadas, isolou-se Salmonella sp. de apenas nove (14,28\%), sendo identificados os sorovares Typhimurium $(79,4 \%)$, Panama $(11,8 \%)$ e Derby $(5,9 \%)$ e um isolado $(2,9 \%)$ caracterizado como $S$. enterica. Determinou-se presença de salmonelas nos seis sistemas em pelo menos uma amostragem, sendo que o maior número de isolamentos ocorreu aos 120 dias de armazenamento. O perfil de resistência a antimicrobianos demonstrou-se variável, sendo que todas as amostras foram sensíveis a amicacina, gentamicina, amoxicilina, neomicina e ciprofloxacina. A resistência a 4 ou mais antimicrobianos esteve presente em 20,6\% dos isolados. Verificou-se maior percentual de resistência após 120 dias de armazenamento no sistema e o índice de multirresitência a antimicrobianos (MAR) total foi de 0,2. O papel que o tratamento de dejetos exerce no nível de resistência de bactérias habitantes do trato gastrintestinal ainda é controverso. Enquanto alguns estudos apontam para um efeito benéfico, representado pela redução do nível de resistência das amostras durante o tratamento, outros afirmam que a passagem pelos sistemas propiciaria a troca de genes entre linhagens bacterianas resultando no aumento da multirresistência. Tal fato foi observado no presente estudo tendo em vista que índice MAR acima de 0,2 é considerado de risco, uma vez que estes microrganismos poderiam agir como reservatórios de genes de resistência para outras bactérias, inclusive aquelas em contato com a população humana. Com base nos resultados, concluiu-se que amostras de salmonelas sobrevivem após 120 dias de armazenamento do dejeto suíno, sendo observada tendência ao aumento no perfil de resistência após este período.

Palavras chave: Salmonella sp., dejeto suíno armazenado, resistência antimicrobiana

\section{Survival and antimicrobial resistance profile of Salmonella sp. in stored pig manure}

Abstract. This study aimed determine the survival and antimicrobial resistance profile of Salmonella sp. samples isolated from swine manure systems plats with capacity for a minimum period of 120 days of wastewater. Of the 63-manure sample analyzed, Salmonella sp. was recovered only in nine $(14.28 \%)$ of them, with serovars Typhimurium (79.4\%), Panama (11.8\%) and Derby (5.9\%) and one isolate (2.9\%) characterized as S. 
enterica. The presence at least one sample of Salmonella was determined in six systems, with the greatest number of isolations occurring at 120 days of storage. The antimicrobial resistance profile proved to be variable, and all samples were sensitive to amikacin, gentamicin, amoxicillin, neomycin and ciprofloxacin. Resistance to four or more antimicrobials was present in $20.6 \%$ of the isolates. There was a higher percentage of resistance after 120 days of storage in the systems and total multidrug resistance index (MAR) was 0.2. The role that waste treatment plays in the level of resistance of bacteria inhabiting the gastrointestinal tract is still controversial. While some studies point to a bneficial effect, represented by reduction of the resistance level of the samples during treatment, others affirm that the passage through the systems would provide the exchange of genes between bacterial strains resulting in an increase in multiresistance. This fact was observed in the present study, considering that the MAR index above 0.2 is considered risk, since these microrganisms could act as reservoirs of resistance genes for other bacteria, including those in contact with the human population. Based on the results, it was concluded that samples of Salmonella survive after 120 days of storage of swine manure, with a tendency to increase in the resistance profile afther this period.

Keywords: Salmonella sp., pig slurry, antimicrobial resistance

\section{Sobrevivencia y perfil de resistencia a los antimicrobianos de aislados de Salmonella sp. en estiércol de cerdo almacenado}

Resumen. Este estudio tuve como objetivo determinar la sobrevivencia y perfil de resistencia a los antimicrobianos de muestras de Salmonella sp. aisladas de seis sistemas de almacenamiento de estiércol porcino. El perfil de resistencia antimicrobiana de Sallmonella sp. fue mensurado en plantas de estiércol de cerdo con capacidad de almacenamiento por un período mínimo de 120 días. De las 63 muestras de estiércol analizadas, se aisló Salmonella sp de tan solo nueve (14.28\%), con los serovares Typhimurium (79.4\%), Panamá (11.8\%) y Derby (5.9\%) y un aislado (2.9\%) caracterizado como S. enterica. La presencia de salmonelas em los seis sistemas se determinó en al menos una muestra, y el mayor número de aislamientos se produjo a los 120 días de almacenamiento. El perfil de resistencia a los antimicrobianos resultó ser variable y todas las muestras fueron sensibles a amikacina, gentamicina, amoxicilina, neomicina y ciprofloxacina. La resistencia a 4 o más antimicrobianos estuvo presente en el 20,6\% de los aislamientos. Hubo un mayor porcentaje de resistencia después de 120 días de almacenamiento en el sistema y el índice total de resistencia a múltiples fármacos (MAR) fue de 0,2. El papel que el tratamiento de residuos juega en el nivel de resistencia de las bacterias que habitan el tracto gastrointestinal sigue siendo controvertido. Si bien algunos estudios apuntan a un efecto beneficioso, representado por la reducción del nivel de resistencia de las muestras durante el tratamiento, otros afirman que el paso por los sistemas proporcionaría el intercambio de genes entre cepas bacterianas resultando en un aumento de multirresistencia. Este hecho fue observado en el presente estudio, considerando que el índice MAR por encima de 0,2 se considera riesgoso, ya que estos microorganismos podrían actuar como reservorios de genes de resistencia para otras bacterias, incluidas las que están en contacto con la población humana. Con base en los resultados, se concluyó que las muestras de salmonela sobreviven después de 120 días de almacenamiento de estiércol porcino, con tendencia a incrementar el perfil de resistencia después de este período.

Palabras clave: Salmonella sp., estiércol porcino, resistencia a los antimicrobianos

\section{Introdução}

Os resíduos são conhecidos por conter bactérias patogênicas, como Salmonella sp. e outros microorganismos, com caráter zoonótico, constituindo um problema de saúde pública (Sahlström, $\underline{2003})$. 
Entre os usos propostos para os dejetos encontra-se a aplicação no solo como fertilizante. Entretanto, este procedimento pode levar à contaminação de cursos de água, em decorrência dos elevados teores de compostos fosforados e nitrogenados. Por isso, existe a necessidade de tratamento dos dejetos animais antes de seu uso na agricultura.

Além disso, patógenos como Salmonella sp., que são excretados nas fezes de animais infectados e clinicamente sadios, podem ser lançados no ambiente e resultar em risco sanitário para animais e homem (Jones, 1980).

As salmonelas são microrganismos relativamente resistentes e podem sobreviver fora do hospedeiro em condições ambientais severas por meses, como nos dejetos, por mais de 77 dias e em temperaturas que variam entre 6 e $47^{\circ} \mathrm{C}$; além disso, possuem capacidade de infectar várias espécies de animais de produção e o homem (Sahlström, 2003).

Por muitos anos a produção animal foi acompanhada pelo uso de antimicrobianos, tanto terapêutico quanto preventivo, em especial os promotores de crescimento. $\mathrm{O}$ uso de antimicrobianos foi acompanhado da emergência de linhagens resistentes em diversos microrganismos, inclusive naqueles patogênicos como, por exemplo, Salmonella spp (Fedorka-Cray et al., 1999).

Bactérias resistentes a antimicrobianos podem ser encontradas no ambiente contaminado com excreta ou efluentes humano, animal ou industrial, local onde sofrem pressão de seleção (Linton, 1988). Neste sentido, o objetivo do presente estudo foi determinar a sobrevivência e o perfil de resistência antimicrobiana de amostras de Salmonella sp. em esterqueiras para o armazenamento de dejetos suínos.

\section{Material e métodos}

Foram monitorados seis sistemas de armazenamento de dejetos suínos na região Sul. Os dejetos liquefeitos eram encaminhados a esterqueiras (Maroso et al., 2003) e nelas permaneciam armazenados por um período mínimo de 120 dias (FATMA, 2003). A primeira amostra de dejetos foi coletada, em cada uma das propriedades, nos canais externos de coleta de dejetos existentes nos galpões de suínos caracterizando-se como o "momento zero" de armazenagem. As demais amostras foram coletadas do lado oposto à entrada dos dejetos na esterqueira (Silva et al., 2008) a uma profundidade mínima de 50 cm e igual distância das bordas, após 30, 60, 90 e 120 dias do "momento zero", totalizando 63 amostras de dejetos em 17 coletas.

Realizou-se a determinação da presença de Salmonella sp. (Pereira et al., 2008), isolando-se 34 colônias confirmadas como Salmonella sp. as quais foram mantidas congeladas para sorotipagem no Instituto Oswaldo Cruz.

A sensibilidade a antimicrobianos foi determinada por difusão em ágar (Clsi, 2005), utilizando-se discos impregnados com cotrimoxazol $(25 \mu \mathrm{g})$, tetraciclina $(30 \mu \mathrm{g})$, ácido nalidíxico $(30 \mu \mathrm{g})$, amicacina $(30 \mu \mathrm{g})$, cloranfenicol $(10 \mu \mathrm{g})$, tobramicina $(10 \mu \mathrm{g})$, estreptomicina $(10 \mu \mathrm{g})$, sulfonamida $(300 \mu \mathrm{g})$, gentamicina $(10 \mu \mathrm{g})$, cefaclor $(30 \mu \mathrm{g})$, amoxicilina $(30 \mu \mathrm{g})$, ampicilina $(10 \mu \mathrm{g})$, neomicina $(30 \mu \mathrm{g}) \mathrm{e}$ ciprofloxacina $(5 \mu \mathrm{g})$.

Determinou-se o índice de multirresistência acumulada (MAR) nas amostras de Salmonella ( $\underline{\text { Schmidt }}$ \& Cardoso, 2003).

\section{Resultados}

Das 63 amostras de dejetos analisadas, isolou-se Salmonella sp. de apenas nove (14,28\%), sendo identificados 34 isolados dos sorovares Typhimurium (79,4\%), Panama (11,8\%) e Derby $(5,9 \%)$ e um isolado $(2,9 \%)$ caracterizado como $S$. enterica.

Determinou-se presença de salmonelas nos seis sistemas em pelo menos uma amostragem, sendo que o maior número de isolamentos ocorreu aos 120 dias de armazenamento (Tabela 1).

Verificou-se resistência aos antimicrobianos: tetraciclina (59\%), sulfonamida (47\%), cotrimoxazol (41\%), ácido nalidíxico (35\%), estreptomicina (24\%), cloranfenicol (15\%), tobramicina (6\%), ampicilina $(5,9 \%)$ e cefaclor (3\%). Todas as amostras foram sensíveis a amicacina, gentamicina, 
amoxicilina, neomicina e ciprofloxacina. Apenas quatro $(11,76 \%)$ amostras foram sensíveis a todos os antimicrobianos, sendo essas amostras pertencentes ao sorovar Panama, e 7 (20,6\%) amostras foram resistentes a 4 ou mais antimicrobianos.

Tabela 1. Número de sistemas de armazenamento de dejetos suínos (esterqueiras) em que se isolaram amostras de salmonelas, segundo o tempo de estocagem.

\begin{tabular}{lc}
\hline Tempo de estocagem (dias) & Número de sistemas \\
\hline 0 & 2 \\
30 & 1 \\
60 & 1 \\
90 & 0 \\
120 & 3 \\
\hline
\end{tabular}

Comparando-se o perfil de resistência dos isolados no início do sistema (zero dias de armazenamento) com os isolados aos 120 dias de armazenamento, com exceção da tetraciclina, verificou-se aumento no percentual de resistência aos antimicrobianos (igura 1).

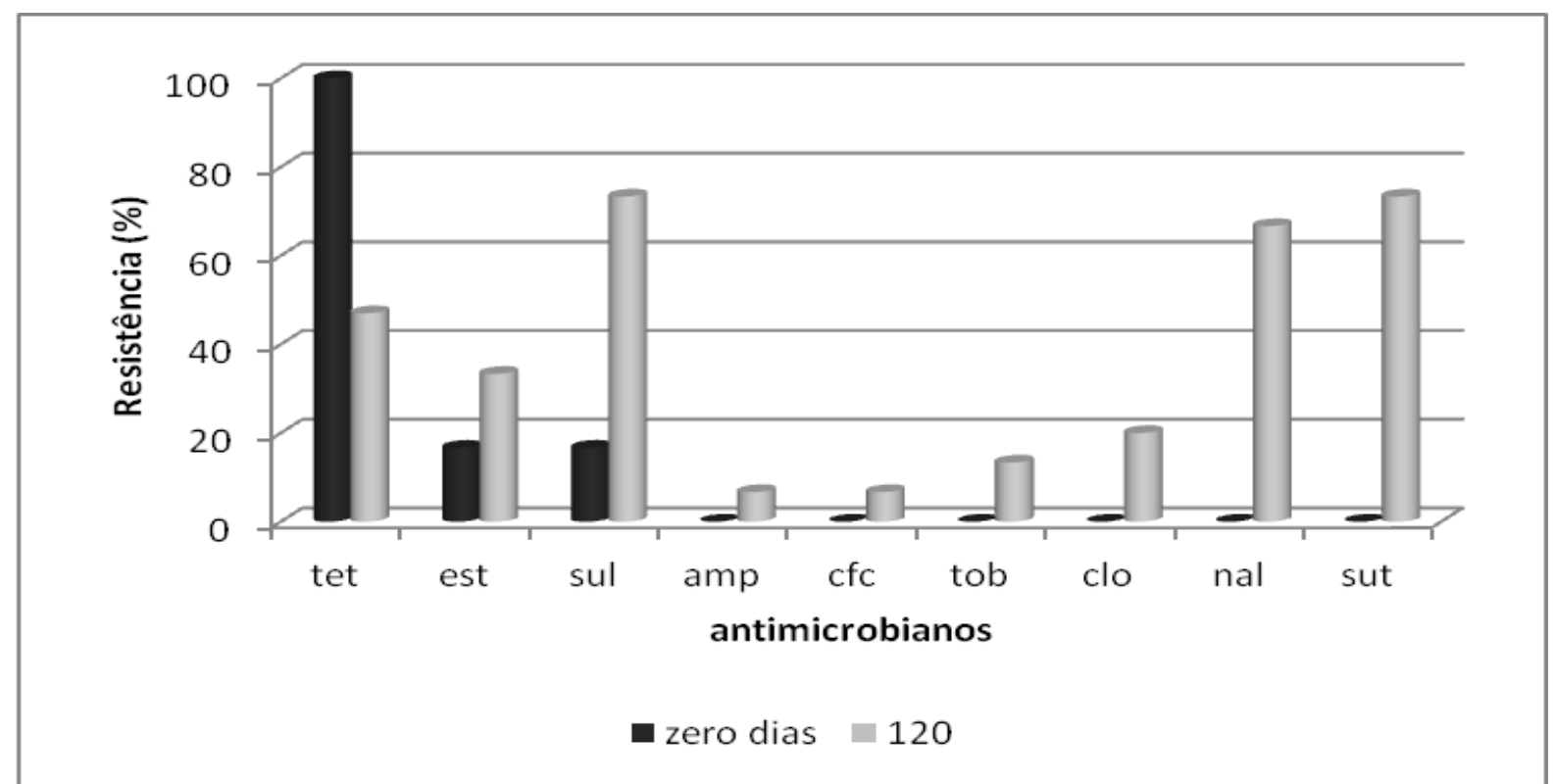

Figura 1. Percentual dresistência a antimicrobianos de isolados de Salmonella aos zero e 120 dias de armazenamento de dejeto suíno.

No presente estudo, as amostras de Salmonella isoladas aos 120 dias de armazenamento eram, em sua maioria, resistentes a 3 antimicrobianos (Tabela 2), diferindo das amostras isoladas aos zero dias de armazenamento, que foram resistentes a somente um antimicrobiano.

Tabela 2. Evolução do perfil de resistência a antimicrobianos de isolados de Salmonella segundo o tempo de armazenagem em esterqueira.

\begin{tabular}{lcccc}
\hline \multirow{2}{*}{ Resistência } & \multicolumn{2}{c}{$\mathrm{N}^{\mathbf{0}}$ de isolados resistentes } & \multicolumn{2}{c}{ Isolados resistentes $(\%)$} \\
\cline { 2 - 5 } 1 antimicrobiano & Zero dias & 120 dias & 66,7 & 120 dias \\
2 antimicrobiano & 8 & 2 & 33,3 & 13,3 \\
3 antimicrobiano & 4 & 0 & 0,0 & 0,0 \\
4 antimicrobiano & 0 & 8 & 0,0 & 53,3 \\
5 antimicrobiano & 0 & 3 & 0,0 & 20,0 \\
8 antimicrobiano & 0 & 1 & 0,0 & 6,7 \\
Total isolados & 0 & 1 & 100 & 6,7 \\
\hline
\end{tabular}

Determinou-se que o índice de multirresistência a antimicrobianos ao zero e 120 dias de armazenamento foi 0,1 e 0,24 , respectivamente. 


\section{Discussão}

A identificação da presença de salmonelas tem sido frequentemente relatada nos diferentes sistemas produtivos suinícolas. No Brasil, a presença de infecção por salmonelas tem sido observada em todas as fases de produção, desde leitões à terminação, com soroprevalência de 78 a 98\% (Kich et al., 2005; Schwarz et al., 2009). Ao abate, os índices de isolamento observados têm sido menores (50 a 79\%) (Bessa et al., 2004; Castagna et al., 2004; Schwarz et al., 2009; Silva et al., 2008). Estudos realizados no Brasil têm registrado isolamentos dos sorovares Derby (Silva et al., 2009), Tiphymurium (Schmidt \& Cardoso, 2003; Bessa et al., 2004; Castagna et al., 2004; Schwarz et al., 2009; Silva et al., 2009), Agona e Panama (Schwarz et al., 2009).

No que se refere à passagem de dejetos contaminados com salmonelas através de sistemas de tratamento aeróbios ou anaeróbios, Juris et al. $(1995,1996)$ apontam a remoção das bactérias presentes. Contudo, no presente estudo este fato não foi observado. Entretanto, em sistemas de lagoas a frequência de isolamentos de salmonelas foi menor, principalmente após o tratamento $(2,5 \%)$ (Schmidt \& Cardoso, 2003). Também na fração em sistemas para o tratamento de dejeto suíno a sobrevivência de salmonelas foi menor tanto no inverno (85 dias) quanto no verão (26 dias), (Plachá et al., 2001). Já em esterqueiras, foi determinada a presença do microrganismo aos 120 dias de armazenamento (Santos et al., 2007).

O isolamento de salmonelas após o armazenamento pode ser decorrente do fato de este microrganismo ser péssimo competidor e, assim, após o declínio na taxa de multiplicação ou inativação de outras bactérias, seria possível isolá-lo laboratorialmente. Por outro lado, este microrganismo pode ser introduzido na granja durante o período de monitoramento do sistema, por meio do próprio homem, equipamentos, utensílios contaminados, roedores, alimentos e água (

$\mathrm{O}$ dejeto armazenado tem como destinação a aplicação sobre o solo. A distribuição de dejetos a menos de $100 \mathrm{~m}$ do local de captação de água possui associação com a soroprevalência de salmonela em suínos (

A crescente preocupação com o surgimento de linhagens bacterianas resistentes a antimicrobianos tem levado à discussão sobre critérios a serem adotados para a escolha de antimicrobianos que possam ser usados em animais e aqueles que devam ser evitados (Webber \& Piddock, 2001). Isto por que, o surgimento de bactérias resistentes está associado à pressão de seleção e à presença de genes de resistência (Witte, 2000), sendo que os genes de resistência podem ser transmissíveis entre diferentes gêneros bacterianos (Schwarz \& Chaslus-Dancla, 2001).

Assim como observado anteriormente em isolados de E.coli (Silva et al., 2008), verificou-se elevados índices de resistência à tetraciclina e à sulfonamida. Em sistema de lagoas para o tratamento de dejetos suínos, Schmidt \& Cardoso (2003) identificaram resistência de S. Typhimurium contra sulfonamida $(100 \%)$, tetraciclina $(99,4 \%)$, estreptomicina $(90,1 \%)$, sulfa/trimetropima $(84,5 \%)$, ácido nalidíxico $(77,6 \%)$, ampicilina $(76,4 \%)$, cloranfenico $(29,2 \%)$, cefaclor $(25,5 \%)$ tobramicina $(13,7 \%)$, gentamicina $(6,2 \%)$, amxoxilina/ácido clavulânico (5\%), neomicina (5\%) e amicacina $(3,7 \%)$.

Diferentemente do observado no presente estudo, em sistema de lagoas foi observado maior percentual de salmonelas resistentes aos antimicrobianos, bem como maior número de amostras multirresistentes $(94,5 \%$ ) (Schmidt \& Cardoso, 2003). Tal fato pode ser decorrente da pressão de seleção ocasionada pelo uso de antimicrobianos ou, ainda, pela transferência de genes de resistência entre bactérias no ambiente (Witte, 2000).

Vários autores têm associado o aumento da resistência bacteriana aos antimicrobianos com a administração excessiva a animais criados para a produção de alimentos

(Cruchaga, 2001; Schwarz \& Chaslus-Dancla, 2001). Por outro lado, o papel que o tratamento de dejetos exerce no nível de resistência de bactérias habitantes do trato gastrintestinal ainda é controverso. Enquanto alguns estudos apontam para um efeito benéfico, representado pela redução do nível de resistência das amostras durante o tratamento, outros afirmam que a passagem pelos sistemas propiciaria a troca de genes entre linhagens bacterianas resultando no aumento da multirresistência (Andersen, 1993; Bell, 1978; Silva et al., 2008). 
Tal fato foi observado no presente estudo tendo em vista que índice MAR acima de 0,2 é considerado de risco, uma vez que estes microrganismos poderiam agir como reservatórios de genes de resistência para outras bactérias, inclusive aquelas em contato com a população humana (Krumperman, 1983).

\section{Conclusão}

Isolaram-se amostras de salmonelas após 120 dias de armazenamento do dejeto suíno, sendo observada tendência ao aumento no perfil de resistência após este período.

\section{Agradecimentos}

À Fundação de Amparo à Pesquisa do Estado do Rio Grande do Sul (FAPERGS - ARD. 03/0385.6) e ao CNPq.

\section{Referências bibliográficas}

Andersen, S. R. (1993). Effects of waste water treatment on the species composition and Antibiotic resistance of coliform bacteria. Current Microbiology, 26(2), 97-103. https://doi.org/10.1007/BF01577343

Bell, R. B. (1978). Antibiotic resistance patterns of fecal coliforms isolated from domestic sewage before and after treatment in an aerobic lagoon. Canadian Journal of Microbiology, 24(7), 886-888. https://doi.org/10.1139/m78-147

Bessa, M. C., Costa, M., \& Cardoso, M. (2004). Prevalência de Salmonella sp em suínos abatidos em frígoríficos do Rio Grande do Sul. Pesquisa Veterinária Brasileira, 24(2), 80-84. https://doi.org/10.1590/S0100-736X2004000200006

Castagna, S. M. F., Schwarz, P., Canal, C. W., \& Cardoso, M. (2004). Presença de Salmonella sp. no trato intestinal e em tonsilas/linfonodos submandibulares de suínos ao abate. Arquivo Brasileiro de Medicina Veterinária e Zootecnia, 56(3), 300-306. https://doi.org/10.1590/S0102-09352004000300003

Cruchaga, S. (2001). Antimicrobial resistance in salmonellae from humans, food and animals in Spain in 1998. Journal of Antimicrobial Chemotherapy, 47(3), 315-321. https://doi.org/10.1093/jac/47.3.315

FATMA. (2003). Fundação do Meio Ambiente -FATMA. Governo Do Estado de Santa Catarina. Portaria $N^{0}$ 002/03 de 09 de Janeiro de 2003.

Fedorka-Cray, P. J., Petersen, K. E., Dargatz, D. A., Tollefson, L., Wineland, N. E., Headrick, M., Hollinger, K., \& Ferris, K. (1999). National antimicrobial resistance monitoring system: Results for swine. International Conference on the Epidemiology and Control of Biological, Chemical and Physical Hazards in Pigs and Pork, 248-249. https://doi.org/10.31274/safepork-180809-1014

Jones, P. (1980). Health hazards associated with the handling of animal wastes. Veterinary Record, 106(1), 4-7. https://doi.org/10.1136/vr.106.1.4

Juris, P., Plachý, P \& Lauková, A. Devitalization of bacterialand parasitic germs in sewage sludge during aerobic digestionunder laboratory conditions. Veterinární medicína, Praga, 40(5), 157-162, 1995

Juris, P., Plachý, P \& Lauková, A. Survival of model bacterial strains and helmintheggs in the course of mesophilic anaerobic digestion of pig slurry. Veterinárni medicína, Praga, 41(5), 149-153, 1996.

Kich, J. D., Mores, N., Piffer, I. A., Coldebella, A., Amaral, A. L., Ramminger, L., \& Cardoso, M. R. I. (2005). Fatores associados à soroprevalência de Salmonella em rebanhos comerciais de suínos. Ciência Rural. Santa Maria., 35(2) (mar./abr.), 398-405.

Krumperman, P. H. (1983). Multiple antibiotic resistance indexing of Escherichia coli to identify highrisk sources of fecal contamination of foods. Applied and Environmental Microbiology, 46(1), 165170.

Linton, A. H. (1988). Plasmids in the environment. Schriftenreihe Des Vereins Fur Wasser-, BodenUnd Lufthygiene, 78, 197-224. http://www.ncbi.nlm.nih.gov/pubmed/3074480

Maroso, M. T. D., Torres, C. A., Borowsky, L. M., Santos, M. A. A., Cardoso, M. R. I., \& Schmidt, V. (2003). Caracterização de sistemas de tratamento de dejetos em unidades integradas de produção de suínos no município de Três Passos, RS. In Anais da $13^{a}$ Mostra de Iniciação Científica da UPF (p. $88)$. 
Pereira, R. A., Canal, C. W., \& Schmidt, V. (2008). Detecção de Salmonella Anatum em ema (Rhea americana). Ciência Rural, 38(3), 823-825. https://doi.org/10.1590/S0103-84782008000300038

Plachá, I., Venglovsky, J., Sasakova, N., \& Svoboda, I. F. (2001). The effect of summer and winter seasons on the survival of Salmonella typhimurium and indicator micro-organisms during the storage of solid fraction of pig slurry. Journal of Applied Microbiology, 91(6), 1036-1043. https://doi.org/10.1046/j.1365-2672.2001.01471.x

Sahlström, L. (2003). A review of survival of pathogenic bacteria in organic waste used in biogas plants. Bioresource Technology, 87(2), 161-166. https://doi.org/10.1016/S0960-8524(02)00168-2

Santos, M. A. A., Schmidt, V., Bitencourt, V. C., \& Maroso, M. T. D. (2007). Esterqueiras: avaliação físico-química e microbiológica do dejeto suíno armazenado. Engenharia Agrícola, 27(2), 537-543. https://doi.org/10.1590/S0100-69162007000300024

Schmidt, V., \& Cardoso, M. R. I. (2003). Sobrevivência e perfil de resistência a antimicrobianos de Salmonella sp. isoladas em um sistema de tratamento de dejetos de suínos. Ciência Rural, 33(5), 881-888. https://doi.org/10.1590/S0103-84782003000500014

Schwarz, P., Calveira, J., Sella, A., Bessa, M., Barcellos, D. E. S. N., \& Cardoso, M. (2009). Salmonella enterica: isolamento e soroprevalência em suínos abatidos no Rio Grande do Sul. Arquivo Brasileiro de Medicina Veterinária e Zootecnia, 61(5), 1028-1034. https://doi.org/10.1590/S010209352009000500003

Schwarz, S., \& Chaslus-Dancla, E. (2001). Use of antimicrobials in veterinary medicine and mechanisms of resistance. Veterinary Research, 32(3/4), 201-225. https://doi.org/10.1051/vetres:2001120

Silva, F. F. P., Santos, M. A. A., \& Schmidt, V. (2008). Resistência a antimicrobianos de Escherichia coli isolada de dejetos suínos em esterqueiras. Arquivo Brasileiro de Medicina Veterinária e Zootecnia, 60(3), 762-765. https://doi.org/10.1590/S0102-09352008000300035

Silva, M. C., Faria, G. S., Paula, D. A. J., Martins, R. P., Caramori Junior, J. G., Kich, J. D., Colodel, E. M., Nakazato, L., \& Dutra, V. (2009). Prevalência de Salmonella sp. em suínos abatidos no Estado de Mato Grosso. Ciência Rural, 39(1), 266-268. https://doi.org/10.1590/S0103-84782008005000035

Webber, M., \& Piddock, L. J. V. (2001). Quinolone resistance in Escherichia coli. Veterinary Research, 32(3/4), 275-284. https://doi.org/10.1051/vetres:2001124

Witte, W. (2000). Ecological impact of antibiotic use in animals on different complex microflora: environment. International Journal of Antimicrobial Agents, 14(4), 321-325. https://doi.org/10.1016/S0924$\underline{8579(00) 00144-8}$

Recebido: 5 de maio, 2020 .

Aprovado: 11 de junho, 2020.

Disponível online: 18 de setembro, 2020.

Licenciamento: Este artigo é publicado na modalidade Acesso Aberto sob a licença Creative Commons Atribuição 4.0 (CC-BY 4.0), a qual permite uso irrestrito, distribuição, reprodução em qualquer meio, desde que o autor e a fonte sejam devidamente creditados. 